\title{
Management of diabetes and dementia
}

\author{
AMAR PUTTANNA, NOUSHAD KULAMBIL PADINJAKARA
}

\begin{abstract}
Continued advances in medicine have contributed to an ageing population in most countries, with a resultant increased prevalence of dementia as well as type 2 diabetes. Consequently, the combined co-morbidity of diabetes and dementia is on the increase. While there is a wealth of therapeutic options for diabetes in general, we need to adapt these medications and strategies to suit those with dementia. The intricacies of managing diabetes in patients with cognitive dysfunction are multiple and require a sound understanding of the patient, living environment and available therapeutic options. With the exception of metformin, dipeptidyl peptidase-4 inhibitors and to some extent insulin secretagogues, non-insulin therapy has a limited role. Insulin therapy, if initiated with a specified goal in mind and concentration on avoidance of hypoglycaemic episodes with relatively lax glycaemic targets, is the most straightforward way of managing glycaemia. Therapy should be individualised with involvement of the patient's care team and clear instructions to define roles, goals of therapy and need for regular review. In this article we discuss the effect of dementia on diabetes management and vice versa, glycaemic goals based on available evidence and recommendations including drug and regimen selection to safely achieve this.

Br J Diabetes 2017;17:93-99
\end{abstract}

Key words: diabetes, dementia, cognitive, management, medication

\section{Introduction}

The link between diabetes and dementia has long been established, with various studies having noted this association. ${ }^{1}$ The DCCT/EDIC study found that glycaemic control was associated with declining cognitive function and the ACCORD-MIND trial noted that, for each $1 \%$ rise in $\mathrm{Hba}_{1}$, there was a 0.14 point drop in MMSE score.2,3 In addition, studies have noted the effects of hypoglycaemia on increasing risk of cognitive impairment. ${ }^{4,5} \mathrm{How}$ -

Department of Diabetes and Endocrinology, Walsall Healthcare NHS Trust, Walsall, UK

Address for correspondence: Dr Amar Puttanna

Department of Diabetes and Endocrinology, Walsall Healthcare NHS

Trust, Moat Road, Walsall WS2 9PS, UK

E-mail: amarputtanna@doctors.org.uk

http://dx.doi.org/10.15277/bjd.2017.139 ever, there is a paucity of information on the management of diabetes and therapeutic options in dementia, as many patients (with dementia) would be excluded from clinical trials designed to test efficacy and safety of diabetes medications.

Diabetes UK has recently published guidelines on managing diabetes in care home residents, ${ }^{6}$ and the International Diabetes Federation (IDF) has published guidelines on managing diabetes in the elderly. ${ }^{7}$ However, these documents, though highlighting certain concepts in managing diabetes in the setting of dementia, do not offer any specific therapeutic guidance.

To help guide practitioners further, a consensus meeting took place to help identify and manage patients, but this too has not specifically discussed medications and therapeutic management in such patients. ${ }^{8}$

There is considerable difficulty in tailoring a diabetes regimen in the setting of chronic cognitive impairment, not least because of the associated memory impairment but also accounting for the various stages of deterioration in cognition, changes to environment or carers and the reduced nutritional intake associated with the cognitive decline including alterations in the method of administration of medicines.

This article will specifically focus on the therapeutic options and management of patients with diabetes and dementia in order to provide some guidance to clinicians in dealing with patients with these comorbid conditions.

\section{Scope of the problem}

Alzheimer's Disease International recently published a report assessing the impact of dementia globally in the next 40 years. ${ }^{9}$ As of 2015 there are 46.8 million people with dementia in the world, with this rising to over 131.5 million by 2050 . In this document they highlighted the significant economic impact of dementia and the likelihood of a further increase. They valued the current cost of dementia globally as being 818 billion dollars as of 2015, with a cost over $£ 23$ billion in the UK alone in 2012. Similarly, Diabetes UK have issued a document on the impact of diabetes and noted that the worldwide prevalence of diabetes in 2015 was 387 million and is due to rise to 592 million by $2035 .{ }^{10}$ In the elderly population, the American Diabetes Association have noted that 11.8 million $(25.9 \%)$ aged over 65 years have diabetes (either diagnosed or undiagnosed). ${ }^{11}$

Patients with diabetes have a greater decline in cognitive performance and are 1.5-2 times more likely to develop dementia than those without. ${ }^{8}$ There are no clear data on the prevalence of both comorbidities in patients; however, a study in USA by Travis et al identified 144,969 patients in nursing homes with diabetes, of 
which more than a third (over 48,323 ) had a moderate degree of cognitive impairment. ${ }^{12}$

From the above figures it is clear to see that the global impact of both these conditions is monumental and the predicted increase in burden of both in the coming decades make it all the more necessary to understand the management of patients with both conditions, as this too will only increase.

\section{Effect of dementia on diabetes management}

Diabetes is largely a self-managed condition and, running up to the diagnosis of dementia, most patients would be managing their glycaemia on their own. Worsening glycaemic control, not turning up for reviews or unexpected hypoglycaemic episodes should alert the clinician towards possible cognitive decline of the patient. Patients may not be able to remember to take medications at appropriate times, to recognise hypo- and hyperglycaemia and take remedial action as we expect from a diabetic patient without cognitive dysfunction. It is important for healthcare professionals to highlight the diagnosis of dementia and take a proactive role in seeing these patients to ensure well-being.

It is necessary to remind clinicians that cognitive decline in a patient with dementia is variable and the management of a patient will depend on the degree of impairment.

A patient with mild cognitive impairment may require more focused assessment including vascular risk and relatively tighter glycaemic management. However, a patient with more advanced dementia may require laxer control with more focus on symptom relief from hypo- or hyperglycaemia and less worry about vascular risks, with quality of life guiding management and treatment goals.

Whilst a patient with early stages of cognitive decline may be able to manage their diabetes themselves, as cognition declines, the compliance with medication may also prove difficult to assess and the onus of management and medication administration may fall to the family and/or carers.

These aspects are central to the management of patients with diabetes and dementia and highlight the importance of individualised care, which is all the more important in this subgroup of patients.

While it is difficult to recommend follow-up frequency, in general it should be fairly robust, taking into consideration the speed of cognitive decline, level of social support and the complexity of diabetes management. Health professionals should assess the knowledge and self-management skills of the patient sensitively at each clinic visit and document it clearly. It is worth noting that, due to the stigma associated with dementia, many patients may hide their difficulties using elaborate reminders and notes.

Dementia is an important risk factor for hypoglycaemia and in such patients can simply present as uncharacteristic behaviour at times, which can easily be misinterpreted as declining mental status. ${ }^{13-15}$ Patients with dysphasia may find it difficult to explain hypoglycaemic episodes even if they recognise it in the first place. Regular monitoring of the meter and discussions with carers should help highlight these episodes.

Another issue is the variability in nutritional intake and weight loss. ${ }^{16} \mathrm{As}$ cognition declines and dementia progresses, patients have reduced appetite and nutritional intake. This will not only affect medication choice and dosing (especially insulin), but also increases the risks of hypoglycaemic episodes. A recent study found that, in patients with dementia, there was a higher risk of hypoglycaemic episodes when managed intensively. ${ }^{17}$ Lack of glycogen stores in the liver due to prolonged lack of nutrition will also add to the difficulty of managing hypoglycaemia and predispose to severe hypoglycaemia (requiring assistance from another person to recover). This will impact the management of such patients in the acute setting where intramuscular glucagon may not have the desired effect.

Together with reduced food intake is the problem of reduced fluid intake and susceptibility to dehydration and acute kidney injury. Many patients with type 2 diabetes may be on ACE inhibitors and/or diuretic antihypertensives which predisposes them to acute kidney injury when fluid intake wains. Substituting these medications with non-nephrotoxic medications would be prudent in patients with noted reduced fluid intake. In addition, oral agents used in the management of diabetes, such as metformin, may need to be substituted or have their dose altered in patients with recurrent episodes of acute kidney injury.

Patients with dementia are more susceptible to infections and generally tend to have other comorbidities. This again will impact on the choice of medication and add to difficulty in achieving appropriate glycaemic control. Intermittent infections not only increase confusion and may prevent appropriate administration of medication, but also risk worsening hyperglycaemia and dehydration. Repeated hospital admissions also add to the difficulty in ensuring stable glycaemia due to disruption in regular feeding habits and nutritional intake. ${ }^{18,19}$ Medications specifically dealing with confusion and agitation in dementia tend to include antipsychotic agents such as olanzapine or risperidone. These medications are well known for their effects on worsening glycaemic control and pose another problem in such patients, with clozapine and olanzapine most frequently reported to affect glycaemia. ${ }^{20,21}$

\section{Effects of diabetes on dementia}

The risks of uncontrolled hyperglycaemia in patients with dementia are significant osmotic symptoms as well as the development of ketoacidosis or hyperosmolar hyperglycaemic state, which further affects morbidity and mortality. This hyperglycaemia would also cause an acute confusional state and significantly accelerate their cognitive decline. ${ }^{22}$

Loss of continence with hyperglycaemia should also be considered in these patients because it contributes to their risk of falls and infection. Weight loss in the face of reasonable food intake should also alert physicians to consider poor glycaemic control in such patients.

Due to the nature of the condition (with baseline altered mental function), presentation with hypoglycaemia may be very different in a patient with dementia and therefore carers and physicians should have a low threshold for suspicion for any unusual behaviour out of context to the patient's norm. Also, as mentioned before, there may be difficulty communicating their altered symptoms.

Nocturnal hypoglycaemia must be avoided due to the risk of 
further cognitive impairment and even potential life-threatening consequences resulting from lack of awareness. ${ }^{23}$ Medication side effects should also be scrutinised in these patients as even simple effects such as gastrointestinal upset can cause significant lifestyle disruption and risk further complications such as dehydration or poorer nutritional intake.

Complications associated with diabetes including cardiovascular risk may also pose a problem. Patients with dementia are not only more likely to have comorbid conditions that will impact on cardiovascular risk but may also not be able to describe issues such as neuropathy or visual disturbances. Assessment of risk and potential of complications such as foot disease is necessary to reduce the burden on both the patients and healthcare team as well as to guide therapeutic decisions and intensification.

\section{Aims of therapy}

There is limited evidence on appropriate targets specifically for patients with dementia. Therapy in these patients should focus less on achieving glycaemic targets and more on symptom control with avoidance of hyperglycaemic or hypoglycaemic episodes.

Diabetes UK has addressed the issue of care home residents and developed guidelines for implementation. ${ }^{6}$ Although not specifically for dementia, they state that, in patients with a history of significant mental illness, the target $\mathrm{HbA}_{1 \mathrm{c}}$ should be $53-64 \mathrm{mmol} / \mathrm{mol}$ with a fasting glucose of 7-8.5 mmol/L and postprandial target (2 hours after meal) 8-12 $\mathrm{mmol} / \mathrm{L}$. They also state that the aim of treatment is to avoid hypoglycaemic episodes and multiple dose adjustments to treatment regimes.

The International Diabetes Federation global guidelines do specifically address the issue of dementia. They state that emphasis should be placed on patient safety with relaxation of glycaemic targets, simplifying regimes and reducing risk of hypoglycaemia or unacceptable hyperglycaemia. ${ }^{7}$ They suggest a target of $<8.5 \%$ $(70 \mathrm{mmol} / \mathrm{mol})$ and highlight the importance of education of carers and/or family members. Blood glucose testing is dependent on circumstances and carried out by a carer/family member.

Even more recently, a national expert working group delivered a position statement on best clinical practice in patients with diabetes and dementia. ${ }^{8}$ Although issuing guidance on managing these conditions concurrently, further details on therapeutic options were limited. They suggested that medication with a lower risk of hypoglycaemia was ideal, with avoidance of sulfonylureas and insulin where possible. They also advised reducing the number of tablets and frequency, if manageable.

The American Diabetes Association specifically discusses older adults in its recent diabetes management document. With regard to pharmacological therapy, they mainly cite cost as the key issue, especially with newer medications. ${ }^{24}$ They also agree that individualised targets are ideal when dealing with such patients and suggest that hypoglycaemia avoidance is the main concern rather than microvascular complications. This is probably due to microvascular complications having less of an impact than macrovascular in terms of morbidity and mortality in this subgroup. The older patient with cognitive impairment may not necessarily live long enough for microvascular complications to develop. As mentioned earlier, how-
Table 1 Comparison of recommendations from leading societies and publications ${ }^{6-8,24}$

\begin{tabular}{|c|c|c|c|}
\hline & $\begin{array}{l}\mathrm{HbA}_{1 c} \\
\text { target }\end{array}$ & $\begin{array}{l}\text { Fasting } \\
\text { target }\end{array}$ & $\begin{array}{l}\text { Postprandial } \\
\text { target }\end{array}$ \\
\hline IDF & $\begin{array}{l}8.5 \% \\
(70 \mathrm{mmol} / \\
\mathrm{mol})\end{array}$ & - & - \\
\hline DUK & $\begin{array}{l}7-8 \% \\
(53-64 \mathrm{mmol} / \\
\mathrm{mol})\end{array}$ & $7-8.5 \mathrm{mmol} / \mathrm{L}$ & $8-12 \mathrm{mmol} / \mathrm{L}$ \\
\hline $\begin{array}{l}\text { Expert working } \\
\text { group statement }\end{array}$ & $\begin{array}{l}7-8 \% \\
(53-64 \mathrm{mmol} / \\
\mathrm{mol})\end{array}$ & 6-9 mmol/L & - \\
\hline $\begin{array}{l}\text { ADA mild- } \\
\text { moderate } \\
\text { cognitive } \\
\text { impairment }\end{array}$ & $\begin{array}{l}<8 \% \\
(64 \mathrm{mmol} / \\
\mathrm{mol})\end{array}$ & $\begin{array}{l}90-150 \mathrm{mg} / \mathrm{dL} \\
(5-8.3 \mathrm{mmol} / \mathrm{L})\end{array}$ & $\begin{array}{l}100-180 \mathrm{mg} / \mathrm{dL} \\
(5.5-10 \mathrm{mmol} / \mathrm{L}) \\
\text { (bedtime target) }\end{array}$ \\
\hline $\begin{array}{l}\text { ADA moderate- } \\
\text { severe cognitive } \\
\text { impairment }\end{array}$ & $\begin{array}{l}<8.5 \% \\
(70 \mathrm{mmol} / \\
\mathrm{mol})\end{array}$ & $\begin{array}{l}100-180 \mathrm{mg} / \mathrm{dL} \\
(5.5-10 \mathrm{mmol} / \mathrm{L})\end{array}$ & $\begin{array}{l}110-200 \mathrm{mg} / \mathrm{dL} \\
(6.1- \\
11.6 \mathrm{mmol} / \mathrm{L}) \\
\text { (bedtime target) }\end{array}$ \\
\hline
\end{tabular}

ADA, American Diabetes Association; DUK, Diabetes UK; IDF, International Diabetes Federation.

ever, the relatively younger patient with mild to moderate cognitive impairment may still need microvascular complication assessment and screening which, as always, should be on a case-by-case basis. Table 1 provides an overview of the recommendations from current societies and publications on recommended targets.

The above guidance does not state specific therapy or the pros and cons of various treatment regimens. The difficulty with regimens is the frequent changes - not just in cognitive ability but also the location of the patient. A patient with dementia may initially be living at home but then subsequently require hospital admission, intermediate care and then residential or care home (or move from one destination to another). The best treatment option is one that requires minimal administration and is easy to follow by any carer or healthcare member and has reduced adverse effects.

Of course all targets and treatment strategies should be individualised for the patient by assessing specific needs or concerns, but certain therapeutic options are less beneficial than others. One guideline that has come close to providing detailed advice on management of patients with diabetes and dementia is the TREND-UK and Institute of Diabetes for Older People (IDOP) 'Diabetes and Dementia Guidance on Practical Management'. Although this guideline describes the importance of hypoglycaemia avoidance and suggests sulfonylurea avoidance and the importance of snacks with insulin, it does not discuss the specifics of medication in these patients; however this will be addressed in more detail below. ${ }^{25}$

\section{Therapeutic options and considerations}

\section{Non-insulins}

There is currently little evidence to suggest that specific treatments in diabetes can improve cognitive function. A Cochrane review was 
unable to find any appropriate studies for meta-analysis and suggests that cognitive function should be considered as an outcome when researching treatment of diabetes. ${ }^{26}$

Interestingly, a large case-control study in the UK found that long-term use of sulfonylureas, thiazolidinediones and insulin was not associated with an increased risk of developing Alzheimer's dementia, but those with long-term metformin use had a slightly higher risk. ${ }^{27}$ However, there are considerable conflicting data on medication and dementia risk, and a review of diabetes medications (metformin, sulfonylureas, thiazolidinediones, dipeptidyl peptidase4 (DPP-4) inhibitors, glucagon-like peptide-1 (GLP-1) receptor agonists and intranasal insulin) and their potential role in treating mild cognitive impairment and Alzheimer's disease found it difficult to conclude whether beneficial effects were due to the neuroprotective effects of the medications or to glucose reduction..$^{28}$

Despite the recent developments in antidiabetic therapy, there are limitations to the use of many non-insulin antidiabetic agents in managing patients with dementia.

Metformin, whilst the mainstay of many diabetic therapeutic options, can cause problems in patients with dementia. The reduced risk of hypoglycaemia episodes is beneficial and the possible improvement in cardiovascular risk is also useful; however, the main limitations are in patients with other comorbidities (eg, heart failure, chronic kidney disease) but also because of the risks of dehydration and acute renal impairment in such patients which can predispose them to lactic acidosis. On balance, the benefits of oral agents suggest they are still useful therapeutic agents in patients with dementia, with careful monitoring of the dehydration risk and comorbidities.

Sulfonylureas are useful in relatively quick control of hyperglycaemia and the side effect of weight gain may not be as much of an issue in such patients who are less likely to be overweight. The increased risk of hypoglycaemia (especially with other comorbidities such as renal or cardiac failure) is the most significant reason why these medications would fall out of favour in those with cognitive decline, especially at higher doses or with longer acting preparations.

The thiazolidinediones improve insulin sensitivity and may be of therapeutic benefit in patients with dementia. The known side effects are not of more concern in those with dementia than in the general population, although there may be limited glycaemic improvement in many patients. Care must be taken with associated comorbidities such as cardiac impairment, oedema and fracture risk, especially with concomitant osteoporosis. Diabetes is an independent risk factor for falls, as too is cognitive impairment, making this side effect an even more important consideration in this group. 29,30

Meglitinides are rapid insulin secretagogues and, due to their short half-life, are a useful therapeutic intervention in dementia patients to reduce risks of hypoglycaemia. ${ }^{31,32}$ As they are given prior to food consumption, they can be administered in erratic eaters who may miss meals. Their use is advocated by the IDF who suggest that the only real barriers are the need for frequent administration before meals, availability and cost. However, in long-term sufferers, pancreatic beta-cell function may be close to zero therefore there may be limited benefit or effect in stimulating secretion in this subgroup. Recent articles have also noted no real difference in hypoglycaemic risk between these agents (repaglinide) and newer generation sulfonylureas, although nateglinide may have lesser effects. ${ }^{31-34}$

DPP-4 inhibitors may be beneficial, especially due to their use in all stages of renal impairment. Their side effect risks are not particularly increased in dementia patients; however, as with thiazolidinediones, there may be limited glycaemic benefit.

GLP-1 receptor agonists have been suggested to be of potential benefit in those with cognitive impairment, with a phase 3 clinical trial ongoing; however such data are inconclusive and require more robust assessment. ${ }^{35-37}$ Although there is a low risk of hypoglycaemia, the effects on weight loss and increasing satiety effects may not be beneficial in this cohort of patients where appetite may already be suppressed. Their limited use in moderate to severe renal impairment also restricts their benefit.

Sodium-glucose cotransporter-2 (SGLT-2) inhibitors are probably not ideal in patients with dementia. The increased risk of candidal infections and urinary tract infections can pose symptomatic

Table 2 Overview of risks and benefits of common non-insulin medications with relevance to patients with dementia

\begin{tabular}{|c|c|c|}
\hline Medication & Benefits of use & Risks of use \\
\hline Metformin & $\begin{array}{l}\text { Low risk hypoglycaemia, } \\
\text { well tolerated }\end{array}$ & $\begin{array}{l}\text { Risk in renal impairment } \\
\text { (dehydration), } \\
\text { gastrointestinal side } \\
\text { effects, comorbidities } \\
\text { can limit use }\end{array}$ \\
\hline Sulfonylureas & $\begin{array}{l}\text { Quick glucose } \\
\text { stabilisation, relatively } \\
\text { well tolerated }\end{array}$ & $\begin{array}{l}\text { Increased risk of } \\
\text { hypoglycaemia, } \\
\text { especially if } \\
\text { comorbidities, risk of } \\
\text { heart failure }\end{array}$ \\
\hline Thiazolidinediones & $\begin{array}{l}\text { Useful but limited } \\
\text { glycaemic control }\end{array}$ & $\begin{array}{l}\text { Long-term effects } \\
\text { (cardiovascular/bladder/ } \\
\text { fracture risk) }\end{array}$ \\
\hline Meglitinides & $\begin{array}{l}\text { Rapid insulin promoting } \\
\text { action, useful in erratic } \\
\text { eaters, possible lower } \\
\text { risk hypoglycaemia }\end{array}$ & Limited availability, cost \\
\hline DPP-4 inhibitors & $\begin{array}{l}\text { Benefit especially in renal } \\
\text { impairment, low risk } \\
\text { hypoglycaemia }\end{array}$ & $\begin{array}{l}\text { Moderate glycaemic } \\
\text { improvement }\end{array}$ \\
\hline GLP-1 agonists & $\begin{array}{l}\text { Low risk hypolycaemia, } \\
\text { good glycaemic } \\
\text { improvement }\end{array}$ & $\begin{array}{l}\text { Weight loss may not be } \\
\text { ideal, satiety effects not } \\
\text { ideal, gastrointestinal } \\
\text { side effects, cost benefit, } \\
\text { may not be effective at } \\
\text { late stage }\end{array}$ \\
\hline SGLT-2 inhibitors & $\begin{array}{l}\text { Good glycaemic } \\
\text { improvement but avoid }\end{array}$ & $\begin{array}{l}\text { Risk of dehydration, } \\
\text { UTIs/thrush and } \\
\text { confusion, comorbidities } \\
\text { limit use }\end{array}$ \\
\hline
\end{tabular}

DPP-4, dipeptidyl peptidase-4; GLP-1, glucagon-like peptide-1; SGLT-2, sodium-glucose cotransporter-2. 
discomfort and agitation for the patient and can also worsen confusion and even cause unnecessary hospital admission. The diuretic effects can also prove problematic in those with incontinence or mobility problems and also increase the risk of dehydration (especially if on concomitant diuretics or nephrotoxics). Multiple visits to the bathroom either in the day or at night also increase the risk of falls in such patients. Table 2 provides a list of common medications and the risks and benefits of their use.

\section{Insulins}

Insulin therapy is the best option for optimally managing glycaemia in patients with diabetes; however, its use in patients with dementia must be carefully reviewed and assessed. The dangers of inappropriate administration need to be considered and the patient's ability to self-administer insulin regularly reviewed. Ideally, a supervising carer or family member should be available or chosen for this role. As cognitive decline increases, the burden of insulin delivery will pass on to the carer, family member or nursing staff. This must also be considered when deciding on the choice of insulin and appropriate regimen.

Basal bolus regimens require a higher degree of mental skill to coordinate the appropriate rapid-acting insulin dose to carbohydrate intake. The risk of inappropriate dosing is higher with this regimen and it can become too confusing for both the patient and the carer or nursing staff. As tight glycaemic control is not required in these patients and due to the multiple injections required, this regimen is not ideal for patients with dementia. However, a modified regimen may have its place. This may involve a basal insulin with 'as required' rapid-acting insulin depending on blood sugar readings to avoid hypoglycaemia, significant hyperglycaemia or ketonaemia. This, of course, will need adept carers and ideally a nursing home situation with 24 hour care due to the risks of hypoglycaemia. A detailed management plan with glycaemic thresholds for administering the rapid-acting insulin must be agreed to by the primary, secondary and carer teams.

Long-acting insulin regimens, either by themselves or in addition to oral therapy, are useful for preventing hyperglycaemia and keeping sugars reasonable without aiming for tight control. Ultralongacting insulin (degludec) may be useful due to reduced nocturnal hypoglycaemic episodes, but only if the patient has recurring hypoglycaemia at night despite other insulin therapy or significant variability in blood sugars with no improvement following dose titration.

Mixed insulins are generally ideal in most patients with dementia requiring insulin therapy who have regular meals. Care needs to be taken in patients who start to reduce their oral intake in order to avoid hypoglycaemic episodes as, in some cases, swinging glucose levels between hypoglycaemic episodes and hyperglycaemia can prove problematic and difficult to control due to the rigidity of mixed insulin dosing. In such situations, insulin administration may sometimes be delayed until sufficient amounts of food have been consumed, accepting the lag time in blood sugar control. However, if assessed regularly, these insulins and regimens can be effective.

Analogue insulins are associated with fewer severe hypoglycaemic episodes and may be of benefit in these patients; however, as tight glycaemic control is not the aim, one could question whether the insulin type would make much difference. ${ }^{38} \mathrm{~A}$ study assessing oral agents versus insulin analogues in nursing home patients, and specifically dementia, found that rapid and long-acting insulin analogues were associated with a reduced risk of hypoglycaemia compared with sulfonylurea or metformin/sulfonylurea combination. 39

\section{Regimens and management suggestions}

The management of patients with diabetes and dementia requires considerable thought and continuous review. There needs to be an ongoing assessment of the patient's self-management skills, not just with food intake but with the ability to administer medication appropriately. This should be extended to the patient's caregivers and their needs or abilities. Specialists should bear both of these in mind when devising an appropriate regimen and deciding glycaemic targets (both of which are subject to change and evolution).

A written glycaemic control plan for individual patients by the specialist teams, especially if they are in a nursing home setting, provides a clear and patient-centred approach aiding clarity for the caregivers and avoiding unnecessary hospital admissions. The previously mentioned TREND guidance discusses the roles of specialists and carers in some detail, as well as their respective roles in assessing nutritional intake, hyperglycaemia and hypoglycaemia management and overall management specifically in a care home setting. ${ }^{25}$

The least complicated and easiest to follow regimen is the most appropriate one for such patients. Oral therapy with a minimal risk of hypoglycaemia - usually metformin or a DDP-4 inhibitor - is the first-line choice; a combination of these agents can be used where a second agent is required. For alternative second-line oral therapy, pioglitazone or rapid-acting secretagogues (meglitinides or short half-life sulfonylureas in low dose) may be acceptable for intensification with due consideration of the risks and benefits compared with insulin therapy. If high doses of sulfonylurea are required or the patient suffers recurrent hypoglycaemic episodes, then medication review is required to evaluate the hypoglycaemia risk and consider insulin therapy (either as sole therapy or with appropriate oral medication), or even stepdown of therapy.

The frequency of $\mathrm{HbA}_{1 \mathrm{c}}$ review is dependent on various individual factors but needs to be appropriate to aid decision making in stepping up or down of therapy. However, it should be at the very least once a year.

\section{Conclusion}

The incidence and prevalence of diabetes and dementia are rapidly rising and adequate time and thought needs to be invested in avoiding uncontrolled diabetes in these patients. Despite the variety of therapeutic options available, there are limited benefits of many therapies in such patients. With the exception of metformin, DPP4 inhibitors and to some extent meglitinides, non-insulin therapy has a limited role. Insulin therapy, if initiated with a specified goal in mind and due consideration on avoidance of hypoglycaemic episodes with relatively lax glycaemic targets, is the most straightforward way of managing glycaemia.

Therapy should be individualised with involvement of the pa- 


\section{Key messages}

- Pharmacological management of diabetes in dementia is important due to the various agents available and potential risks associated with each agent.

- Individualised care plans regarding therapeutic management should be planned and implemented by physicians/multidisciplinary teams to ensure safe and careful management.

- When considering oral therapy, agents such as metformin, DDP-4 inhibitors and rapid insulin secretagogues are suggested.

- SGLT-2 inhibitors, GLP-1 agonists and sulfonylureas are probably best avoided due to side effects that have specific implications in patients with dementia.

- When considering insulin, long-acting insulin in combination with oral therapy or insulin therapy on its own is recommended.

- Regular assessment of patient understanding and administration should take place and a responsible healthcare professional should be tasked with reviewing whether the current regimen is appropriate.

tient's care team, and clear instructions need to be put in place to define roles, goals of therapy and need for regular review.

\section{Conflict of interest None. Funding None.}

Author contributions AP and RNKP were involved in all aspects of this article and both wrote the article with RNKP directing the content and reviewing the document.

\section{References}

1. Yaffe K, Falvey C, Hamilton N, et al. Diabetes, glucose control, and 9-year cognitive decline among older adults without dementia. Arch Neurol 2012;69:1170-5. http://dx.doi.org/10.1001/archneurol.2012.1117

2. Diabetes Control and Complication Trial/Epidemiology of Diabetes Intervention and Complications (DCCT/EDIC) Study Research Group. Long-term effect of diabetes and its treatment on cognitive function. $N$ Engl J Med 2007:356:1842-52. http://dx. doi.org/10.1056/NEJMoa066397

3. Cukierman-Yaffe T, Gerstein HC, Williamson JD, et al. Relationship between baseline glycaemic control and cognitive function in individuals with type 2 diabetes and other cardiovascular risk factors. The Action to Control Cardiovascular Risk in Diabetes-Memory in Diabetes (ACCORD-MIND) trial. Diabetes Care 2009;32:221-6. http://dx.doi.org/10.2337/dc08-1153

4. Whitmer RA, Karter AJ, Yaffe K, et al. Hypoglycaemic episodes and risk of dementia in older patients with type 2 diabetes mellitus. JAMA 2009;301:1565-72. http://dx.doi.org/10.1001/jama.2009.460

5. Asvold BO, Sand T, Hestad K, et al. Cognitive function in type 1 diabetic adults with early exposure to severe hypoglycaemia. A 16 year follow up study. Diabetes Care 2012;33:1945-7. http://dx.doi.org/10.2337/dc10-0621

6. Diabetes UK. Good Clinical Practice Guidelines for Care Home Residents with Diabetes. A revision document prepared by a Task and Finish Group of Diabetes UK, January 2010. https://www. diabetes.org.uk/Documents/About\%20Us/Our\%20views/Care\%20recs/Care-homes0110.pdf (accessed 10th September 2016)
7. International Diabetes Federation. Managing Older People With Type 2 Diabetes: Global Guideline. 2013. https://www.idf.org/e-library/guidelines/78-global-guideline-for-managing-older-people-with-type-2-diabetes.html (accessed 6th September 2017)

8. Sinclair AJ, Hillson R, Bayer AJ, on behalf of a National Expert Working Group. Diabetes and dementia in older people: a Best Clinical Practice Statement by a multidisciplinary National Expert Working Group. Diabet Med 2014;31:1024-31. http://dx.doi.org/10.1111/dme.12467

9. Alzheimer's Disease International. World Alzheimer Report. The Global Impact of Dementia: an Analysis of Prevalence, Incidence, Cost and Trends. 2015. https://www.alz.co.uk/research/WorldAlzheimerReport 2015.pdf (accessed 6th September 2017)

10. Diabetes: Facts and Stats Version 4, revised May 2015. https://www.diabetes.org.uk/Documents/Position\%20statements/Facts\%20and\%20st ats\%20June\%202015.pdf (accessed 29 Aug 2015).

11. American Diabetes Association. Statistics about Diabetes: Overall Numbers, Diabetes and Prediabetes. http://www.diabetes.org/diabetes-basics/statistics/?loc=superfooter (accessed 26 Aug 2015)

12. Travis SS, Buchanan RJ, Wang $S$, et al. Analyses of nursing home residents with diabetes at admission. J Am Med Dir Assoc 2004;5:320-7.

13. Bruce DG, Davis WA, Casey GP, et al. Severe hypoglycaemia and cognitive impairment in older patients with diabetes: the Fremantle Diabetes Study. Diabetologia 2009;52:1808-15. http://dx.doi.org/10.1007/s00125-009-1437-1

14. Punthakee Z, Miller ME, Launer LJ, et al. Poor cognitive function and risk of severe hypoglycaemia in type 2 diabetes. Post hoc epidemiological analysis of the ACCORD trial. Diabetes Care 2012;35:787-93. http://dx.doi.org/10.2337/dc11-1855

15. Lekarcyk JA, Himmel L, Munshi M. Blood glucose monitoring and underlying question of hypoglycaemia are both essential to preventing hypoglycaemia in nursing home residents. Clin Diabetes 2013;31(1).

16. Ikeda M, Brown J, Holland AJ, et al. Changes in appetite, food preference, and eating habits in frontotemporal dementia and Alzheimer's disease. J Neurol Neurosurg Psychiatry 2002;73:371-6.

17. Feil DG, Rajan M, Soroka O, et al. Risk of hypoglycemia in older veterans with dementia and cognitive impairment: implications for practice and policy. J Am Geriatr Soc 2011;59:2263-72. http://dx.doi.org/10.1111/j.1532-5415.2011.03726.x

18. Davydow DS, Zivin K, Katon WJ, et al. Neuropsychiatric disorders and potentially preventable hospitalizations in a prospective cohort study of older Americans. J Gen Intern Med 2014;29:1362-71.

http://dx.doi.org/10.1007/s11606-014-2916-8

19. Phelan EA, Borson $S$, Grothaus $L$, et al. Association of incident dementia with hospitalizations. JAMA 2012;307:165-72. http://dx.doi.org/10.1001/jama.2011.1964

20. Haupt DW, Newcomer JW. Hyperglycemia and antipsychotic medications. J Clin Psychiatry 2001:62(Suppl 27):15-26; discussion 40-1.

21. Lindenmayer JP, Nathan AM, Smith RC. Hyperglycemia associated with the use of atypical antipsychotics. I Clin Psychiatry 2001;62(Suppl 23):30-8.

22. Sommerfield AJ, Deary IJ, Frier BM. Acute hyperglycemia alters mood state and impairs cognitive performance in people with type 2 diabetes. Diabetes Care 2004;27:2335-40.

23. Gerstein HC, Miller ME, Byington RP, et al, on behalf of Action to Control Cardiovascular Risk in Diabetes Study Group. Effects of intensive glucose lowering in type 2 diabetes. N Engl J Med 2008;358:2545-59. http://dx.doi.org/10.1056/NEJMoa0802743

24. American Diabetes Association. Section 10. Older adults. Standards of Medical Care in Diabetes. 2015. Diabetes Care 2015;38(Suppl 1): S67-S69. https://doi.org/10.2337/dc15-S013

25. TREND-UK/IDOP. Diabetes and Dementia Guidance on Practical Management. https://www.diabetes.org.uk/Documents/Professionals/Professional\%20resources/Diabetes_And_Dementia_Guidance_2013.pdf (accessed 1 June 2017).

26. Evans JG, Sastre AA. Effect of the treatment of type II diabetes mellitus on the development of cognitive impairment and dementia. Cochrane Database Syst Rev 2003(1).

27. Imfield P, Bodmer M, Jick SS, Meier CR. Metformin, other antidiabetic drugs and risk of Alzheimer's disease: a population based case control study. J Am Geriatr Soc 2012;60:916-21.

28. Alagiakrishnan K, Sankaralingam S, Ghosh M, et al. Antidiabetic drugs 
and their potential role in treating mild cognitive impairment and Alzheimer's disease. Discov Med 2013;16:277-86.

29. Maurer MS, Burcham J, Cheng H. Diabetes mellitus is associated with an increased risk of falls in elderly residents of a long term care facility. J Gerontol A Biol Sci Med Sci 2005;60:1157-62.

30. Shaw FE. Falls in cognitive impairment and dementia. Clin Geriatr Med 2002:18:159-73.

31. Rosenstock J, Hassman DR, Madder RD, et al. Repaglinide versus nateglinide monotherapy: a randomized, multicenter study. Diabetes Care 2004; 27:1265-70

32. Kristensen JS, Frandsen KB, Bayer $\mathrm{T}$, et al. Compared with repaglinide, sulfonylurea treatment in type 2 diabetes is associated with a 2.5-fold increase in symptomatic hypoglycemia with blood glucose levels $<45$ mg/dl (abstract). Diabetes 2000;49(Suppl 1):A131.

33. Bolen S, Feldman L, Vassy J, et al. Systematic review: comparative effectiveness and safety of oral medications for type 2 diabetes mellitus. Ann Intern Med 2007:147:386-99.

34. Boyle PJ, Zrebiec J. Impact of therapeutic advances in hypoglycemia in type 2 diabetes. Diabetes Metab Res Rev 2008;24:257-85. http://dx.doi.org/10.1002/dmrr.795
35. ClinicalTrials.gov. Cognitive dysfunction and glucagon-like peptide-1 agonists. https://clinicaltrials.gov/ct2/show/NCT02423824 (accessed 29 Aug 2015).

36. Li Y, Duffy KB, Ottinger MA, et al. GLP-1 receptor stimulation reduces amyloid- $\beta$ peptide accumulation and cytotoxicity in cellular and animal models of Alzheimer's disease. J Alzheimers Dis 2010;19:1205-19. http://dx.doi.org/10.3233/JAD-2010-1314

37. Hölscher C. Potential role of glucagon-like peptide-1 (GLP-1) in neuroprotection. CNS Drugs 2012;26:871-82.

http://dx.doi.org/10.2165/11635890-000000000-00000

38. Horvath $\mathrm{K}$, Jeitler $\mathrm{K}$, Berghold $\mathrm{A}$, et al. Long-acting insulin analogues versus NPH insulin (human isophane insulin) for type 2 diabetes mellitus. Cochrane Database Syst Rev 2007(2).

http://dx.doi.org/10.1002/14651858.CD005613.pub3

39. Abbatecola AM, Bo M, Barbagallo $M$, et al. Severe hypoglycaemia is associated with antidiabetic oral treatment compared with insulin analogs in nursing home patients with type 2 diabetes and dementia: results from the DIMORA study. J Am Med Dir Assoc 2015;16:349.e7-12. http://dx.doi.org/10.1016/j.jamda.2014.12.014
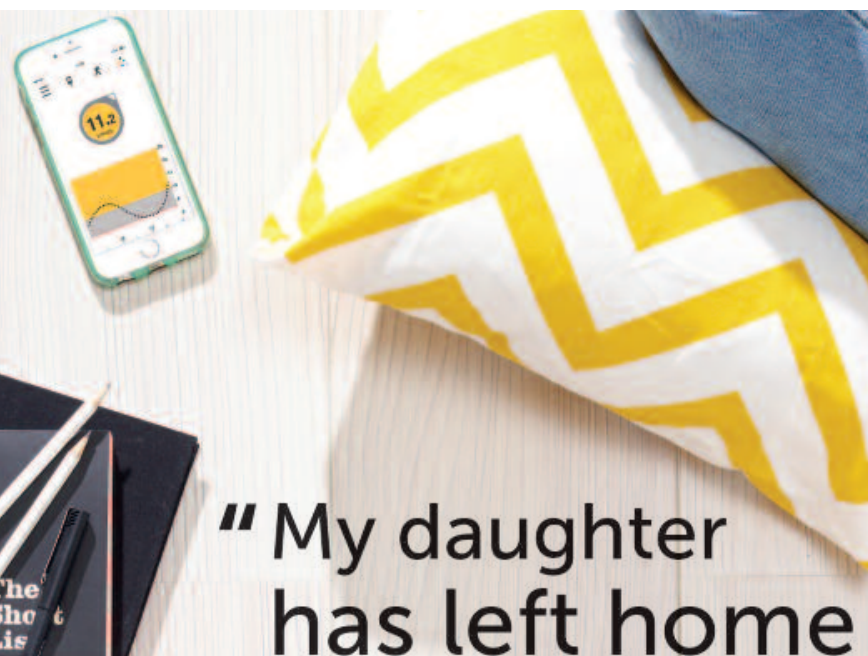

for the first time. I miss her terribly but with the Dexcom Follow* App I can still feel connected, involved and in many ways she is still close.

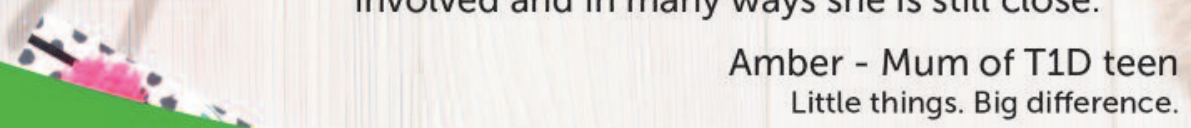
Amber - Mum of T1D teen Little things. Big difference.

Dexcom

CONTINUOUS GLUCOSE MONITORING
With Dexcom‡, your patients and their families can stay connected with real-time data sharing on compatible smart devicest.

Discover how at www.dexcom.com/littlethings 